\title{
Notiz über die Umwandlung von Zimtsäure in Styrol durch Schimmelpilze.
}

\author{
Von
}

R. O. Herzog und O. Ripke.

(Aus dem chemischen Institut der technischen Hochschule zu Karlsruhe.)

(Der Redaktion zugegangen am 11. August 1908.)

Nach der Theorie von Engler stellt das Petroleum die Reste zugrunde gegangener Organismen früherer geologischer Perioden dar; Kohlenhydrate und Proteinstoffe sind mehr oder weniger vollständig durch Mikroorganismen vernichtet worden, während die Fette und Wachse nach ihrer Verseifung zu Fettsäuren wohl das wesentliche Ausgangsmaterial für die Entstehung von Petroleum bilden. Gründe verschiedener Art führen dazu, ${ }^{1)}$ anzunehmen, daß aus den Fettsäuren durch Vorgänge, die sich der im Laboratorium ausgeführten Methode der Druckdestillation in ihrer Wirkung vergleichen lassen, Kohlenwasserstoffe entstehen, die sich durch Polymerisation allmählich in Erdöl umwandeln. Immerhin war der Gedanke nicht völlig von der Hand zu weisen, ob nicht auch noch bei dem ersten Schritt der Erdölbildung aus Fett nach seiner Verseifung bei der Bildung von Kohlenwasserstoffen aus den Fettsäuren Mikroorganismen Anteil nähmen, wenn auch die vorhandenen Versuche über Fettspaltung durch Mikroorganismen von Sommeruga, $\left.{ }^{2}\right)$ Rubner, $\left.{ }^{3}\right)$ Spitta, ${ }^{4}$ Schreiber ${ }^{5}$ ) u. a. keinen

Berlin 1907.

2) Vgl. Engler, Neuere Ansichten über die Entstehung des Erdöls.

2) Zeitschrift f. Hyg., Bd. XVIII, S. $4 \notin 1$.

3) Archiv f. Hyg., Bd. XXXVIII, S. 67.

4) Archiv f. Hyg., Bd. XXXVIII, S. 247.

5) Archiv f. Hyg., Bd. XLI, S. 328, Bd. LXV, S. 295. Vgl. ferner Salkowski, Diese Zeitschrift, Bd. XV, S. 321; ders., Zur Kenntnis der 
Beleg dafür erbringen. In diesem Sinne war eine Mitteilung von Oliviero ${ }^{1}$ ) von Interesse, daß Schimmelpilze - Aspergillus niger und Penicillium glaucum - aus Zimtsäure Styrol zu bilden vermögen. Da diese Umwandlung auch biologisches Interesse bot, haben wir die sehr knappen Angaben Olivieros auf Ersuchen des Herrn Geheimrates Engler nachgeprüft und teilen sie im folgenden mit, nachdem wir auch in der Literatur $^{2}$ ) Zweifel an der Richtigkeit der von Oliviero entdeckten Tatsache gefunden haben. ${ }^{3}$ )

Einige Vorversuche hatten ergeben, daß eine Lösung von $1 / 4 \%$ Zimtsäure - am besten mit $\mathrm{NH}_{3}$, nicht mit $\mathrm{KOH}$ oder $\mathrm{NaOH}$ neutralisiert - in verdünnter Bierwürze gelöst einen ziemlich guten Nährboden für Aspergillus niger, einen etwas weniger guten für Penicillium glaucum abgab. Impft man 41 einer solchen Nährlösung in einem 8 l-Kolben mit reichlich Sporen, eventuell einigen gut gewachsenen Rasenstücken von Aspergillus niger, so tritt bei Zimmertemperatur bereits nach 3 Tagen der dem verdünnten Styrol eigentümliche Geruch nach Leuchtgas durch den Wattestopfen der Flasche hindurch auf. Man ersetzt jetzt steril den Watteverschluß des Kolbens durch einen doppelt gebohrten Kautschukpfropfen, der zwei Glasröhren wie bei den Spritzflaschen üblich trägt, und bläst das gebildete Styrol mit Hilfe eines recht kräftigen sterilen Luftstroms in möglichst wirksame Absorptionsgefäße (z. B. 10-Kugelrohr), die mit $\mathrm{CS}_{2}$ gefüllt sind; an der letzten Absorptionsflasche ist zweckmäßig ein Rückflußkühler angebracht. Schon nach 36 Stunden ist reichlich Styrol im $\mathrm{CS}_{2}$ gelöst.

Fettwachsbildung, Festschrift z. 71. Geburtstage Virchows, 1891 ; Laxa, Arch. f. Hyg., Bd. XLI, S. 119; Hanaus und Štocký, Zeitschrift für Unters. d. Nahrungs- u. Genußm., 1900, S. 606; Reinmann, Zentralblatt f. Bakt., II. Abt., Bd. VI (1900), S. 131; Vogel, D. landw. Pr., Bd. XXIII, Nr. 76 im 11. Jahrg. d. Jahresb. d. Landw., 1876, u. a.

1) Journ. de Pharm. et de Chim., 6e Sér., Bd. XXIV, (1906), II. Teil.

2) Lafar, Handb. d. Techn. Mykologie, Bd. I, S. 687.

s) Über die Bildung von Kohlenwasserstoffen auf biochemischem Wege - abgesehen von der Methanbildung - vgl. auch Weinlandt, Z. f. Biologie, Bd. XLVIII, S. 87 (1906): ferner B. B., Bd. XXV (1892), S. 1489, und Rahn, Zentralbl. f. Bakt., II. Abt., Bd. XVI, S. 383 (1906). 
Der Nachweis erfolgte durch Anlagerung von $\mathrm{Br}_{2}$ im Sonnenlicht unter Bildung von

$$
\mathrm{C}_{6} \mathrm{H}_{5} \mathrm{CHBr} \mathrm{CH}_{2} \mathrm{Br} \text {, }
$$

nachdem wir uns durch Vorversuche überzeugt hatten, daß wir damit eine so gut wie quantitative Methode zum Nachweis auch von wenig Styrol in Händen hatten.

Man geht so vor, daß man eine etwa $6 \%$ ige Bromschwefelkohlenstoff lösung der Styrolschwefelkohlenstofflösung im Sonnenlicht tropfenweise unter Umschütteln zufügt, bis eben keine Entfärbung mehr erfolgt. Hierauf läßt man den Schwefelkohlenstoff bei Zimmertemperatur verdunsten, löst den Rückstand in möglichst wenig heißem Alkohol und fällt mit Wasser aus; wenn nötig, wird dies wiederholt.

Die Schmelzpunktbestimmung des rein weißen, charakteristisch riechenden Produktes ergab 72,3 ${ }^{\circ}$, was mit den Angaben von Miller $\left.{ }^{1}\right)\left(73^{\circ}\right)$, Erdmann $\left.{ }^{2}\right)\left(72-73^{\circ}\right)$ und Schramm $\left.{ }^{3}\right)$ $\left(72-72,5^{\circ}\right)$ gut übereinstimmt.

Die Brombestimmungen ergaben:

$\begin{array}{cccc}\text { Substanz in } \mathrm{g} & \mathrm{AgBr} \text { in } \mathrm{g} & \% \mathrm{Br} \text { gefunden } & \% \mathrm{Br} \text { berechnet } \\ 0,2836 & 0,4000 & 60,01 & 60,57 \\ 0,2364 & 0,3342 & 60,15 & \\ 0,1990 & 0,2810 & 60,10 & \end{array}$

Wir können also die Behauptung von Oliviero vollauf bestätigen. Weiters folgt, daß sich in der Natur Kohlenwasserstoffe wohl auf biologischem Wege aus Fettsäuren bilden könnten, eine Frage, die einer eingehenderen Untersuchung wert wäre.

1) B. B., Bd. XI, S. 14.501 (1878).

2) Liebigs Ann., Bd. CCXVI, S. 194 (1885).

${ }^{3}$ ) B. B., Bd. XVIII, S. 354 (1885). - Radziszewski gibt $68-69^{\circ}$ an (B. B., Bd. VI, S. 194 [1873]), Breuer u. Zincke 73,5-74 C. (B. B., Bd. XI, S. 1399 [1878]). - Ein Präparat, das wir aus Kahlbaumschen Styrol hergestellt hatten, zeigte den Schmelzpunkt bei $71,4^{\circ}$, war aber wahrscheinlich mit etwas polymerisiertem Styrol verunreinigt. 